\title{
Potential Role of Community Pharmacists in Pharmacovigilance: The Effectiveness of an Educational Intervention in Greater Cairo Province in Egypt
}

\section{Mohamed A Elhawary ${ }^{1,2}$, Rehab Mehriz ${ }^{3}$, Moataz E Mohamed ${ }^{4}$, Edrees Helmy $^{2}$, Hadir Rostom ${ }^{1,5}$, Mohamed Solayman ${ }^{6}$ and Nagwa A Sabri ${ }^{6 *}$}

${ }^{1}$ International Society of Pharmacovigilance (ISoP) - Egypt Chapter, Cairo, Egypt

${ }^{2}$ Faculty of Pharmacy, Ain Shams University, Cairo, Egypt

${ }^{3}$ Egyptian Drug Information Centre (EDIC), the Egyptian Drug Authority, Cairo,

Egypt

${ }^{4}$ Department of Pharmacy Practice, Faculty of Pharmacy, Helwan University, Cairo,

Egypt

${ }^{5}$ Egyptian Pharmaceutical Vigilance Center (EPVC), the Egyptian Drug Authority,

Cairo, Egypt

${ }^{6}$ Clinical Pharmacy Department, Faculty of Pharmacy, Ain Shams University, Cairo,

Egypt

*Corresponding Author: Nagwa A Sabri, Clinical Pharmacy Department, Faculty of Pharmacy, Ain Shams University, Cairo, Egypt.
Received: January 28, 2021

Published: February 25, 2021

(C) All rights are reserved by Nagwa A Sabri., et al.

\begin{abstract}
Background: Pharmacovigilance (PV) is a potential tool to avoid and minimize adverse drug reactions (ADRs). Community pharmacists play a pivotal role in detecting and reporting ADRs. As the pharmacovigilance is still new in Egypt, It is crucial to understand the current status among Egyptian community pharmacists towards ADRs reporting and PV side by side with assessing the efficacy of an education intervention aimed to improve their PV knowledge, attitudes and practices before initiating any national educational programs.

Results: A total number of 792 community pharmacists participated with an overall response rate of 78.18\%. The majority (63.89\% and $70.96 \%$ ) of the participating community pharmacists had inadequate prior knowledge concerning of the definitions of PV and ADRs, respectively. The educational intervention was found to be an effective tool as the median (interquartile range [Q1 - Q3]) for knowledge score was increased from 4 [3-5] to 7 [7-7] after the session was introduced (p-value $<0.001$ ). Despite the overall positive attitude, only two pharmacists $(0.25 \%)$ declared that they had previously reported an ADR. The main reason for underreporting was stated as (77.02\%) of the participants do not know about the existence of Egyptian Pharmaceutical vigilance Center and ARDs reporting process.

Conclusion: Egyptian community pharmacists require more education and awareness on PV to enhance their knowledge and promote ADRs reporting. The positive attitude on ADRs and PV confined by the community pharmacists would further improve the outcome of these educational interventions.

Keywords: Pharmacovigilance (PV), Adverse Drug Reactions (ADRs), Safety Monitoring, Educational Intervention, Knowledge and Egyptian Pharmaceutical vigilance Center (EPVC).
\end{abstract}

\section{Background}

Adverse drug reaction (ADR) is defined by World Health Organization (WHO) as "a response to a drug which is noxious and un- intended"; this includes medication errors, drugs misuse, abuse, off label use, reactions associated with unlicensed and/or counterfeit medicines, reactions occurring at overdose and due to occupation- 
al exposure [1]. In addition to its economic burden and unwanted influence on the quality of life, ADRs are one of the major health problems that are leading to a significant increase in morbidity and mortality $[2,3]$. Therefore, it is vital for healthcare professionals (HCPs) to know how and where to report an ADR. Evaluating and monitoring the safety of drugs is essential to prevent or decrease drug related problems $[4,5]$.

Several reports [1,5-8], including those published by the WHO, have focused on raising awareness of the magnitude of the drug safety problem and aimed at convincing HCPs that reporting of ADRs is one of their moral and professional obligations. Underreporting of ADRs represent a major problem worldwide; this problem is more obvious in developing countries, like Egypt, due to lack of medication monitoring and prioritization of medication safety or even lack of an ADR reporting system [4,9-11].

Pharmacovigilance (PV) is defined by WHO as " The science and activities relating to the detection, assessment, understanding and prevention of adverse effects or any other drug-related problems" [1]. Pharmacovigilance aims at enhancing medication safety and consequently patient safety by assessing the risk-benefit value of medicinal products. Therefore, it is crucial for every country to develop its own national PV program. Similar to Egypt, Many countries in the Middle East region are members of the WHO Program for International Drug Monitoring [4,9,12,13].

Although Egypt is a member since 2001, no actual steps were achieved till the establishment of The Egyptian Pharmaceutical vigilance Center (EPVC) in 2009 [14]. The Egyptian national ADRs reporting systems is integrated to Sweden- Uppsala Monitoring System (UMC) which is the field name of the World Health Organization's (WHO) collaborating center for International Drug Monitoring [15].

EPVC roles include: receiving ADRs reporting, detecting safety signals, issuing regular newsletter with pharmacovigilance (PV)related updates and conducting awareness workshops [16]. Reporting ADRs in Egypt is a voluntary process, where community pharmacists among other HCPs, can send an ADRs report using a pre-structured form called a Yellow Card to the EPVC [17] aims and objectives Hospital pharmacists can promote medication safety through spontaneous reporting of adverse drug reactions (ADRs.
Along with other HCPs, community pharmacists who work in chain or individual pharmacies represent the primary source of scientifically valid information regarding therapeutic use of medications [18]. They routinely provide medication therapy recommendations to patients and other HCPs that contribute eventually to improved health and promote patient safety; thus, a major responsibility of voluntary ADRs reporting is lying on community pharmacists $[18,19]$.

Studies have shown that optimizing knowledge, attitudes and practices with regard to $\mathrm{PV}$ is important in formulating strategies to encourage ADR reporting $[9,20]$.

Therefore, this study aimed to assess the pre-existing knowledge of ADRs and PV among Egyptian community pharmacists in the Greater Cairo Province and introduce a short educational intervention to assess its efficacy in the improvement in their knowledge level. Moreover, the study aimed to capture their attitudes and practices.

\section{Methods}

Study design

This was a cross sectional and quasi experimental study that was conducted between February 2018 and April 2018 in Greater Cairo region, Egypt.

A random and convenient sample of pharmacists working in either chain or individual pharmacies was invited to participate voluntarily in the study and was provided with the necessary information about the aim of the study. Only licensed community pharmacists were eligible to participate. The study was approved by Faculty of Pharmacy - Ain Shams University, Cairo, Egypt. All pharmacists were informed about the study and asked for a verbal informed consent prior to enrollment.

The pharmacist interview included two questionnaires; a presession and a post-session questionnaire and there was a 15 to 20 minutes of educational session that was introduced in between the two questionnaires. Under the supervision of EPVC, the interviewers were well trained before the start of the data collection process. Questionnaires with missing information were excluded from analysis. 


\section{Educational session}

The educational session was provided to the each pharmacist individually as oral and written material in a period of 15 to 20 minutes and was aimed to increase the awareness and knowledge about community pharmacists' roles towards ADRs, PV and the ADRs national reporting system. The session covered an introduction about the definition of pharmacovigilance, ADRs definition, EPVC role, how to recognize the ADRs in patients and finally how to report them if it is suspected that a patient has experienced any of adverse drug reaction (ADR), drug interaction, misuse or unlicensed use of medicine, treatment errors and defects in pharmaceutical products it should be reported to the EPVC by using a Yellow Card.

\section{Survey construction}

The questionnaires were developed in English language after literature review of published studies with similar objectives and most of the questions were obtained from a published study by Torwane., et al. [21]. The questionnaires were designed as closed-ended questions which were aimed to capture the knowledge, attitudes and practices of the participating pharmacists as well as measuring the degree of improvement in their knowledge after giving them a brief session after the pre-session questionnaire. The complete survey was validated through content validation by the EPVC. The validation process followed the guidelines published by Burns., et al. [22] investigators administer questionnaires to clinicians about their knowledge, attitudes and practice2,4,5 to generate or refine research questions and to evaluate the impact of clinical research on practice. Questionnaires can be descriptive (reporting factual data. The pre-session questionnaire consisted of only one section of seven questions measuring the pre-existing knowledge about ADRs and PV. While, the post-session questionnaire consisted of three sections; the first section was the same questions as the presession questionnaire followed by four questions of the attitude section and ends with six questions on PV related practices. For scoring, each correct answer was given a mark of 1 and incorrect answers were given a zero mark with a maximum cumulative score of 7. The overall score for the sample were classified according to Bloom's cut-off. The knowledge score of $\geq 80 \%$ were considered of good level, and score between $60-79 \%$ were considered fair while scoring $<60 \%$ were assigned as insufficient level.

\section{Statistical analysis}

All the statistical analyses were done using Excel (Microsoft office 365; Microsoft, Washington, U.S.) and IBM SPSS (version 22; SPSS Inc., Chicago, U.S.). Numbers and Percentages were used to present questionnaire responses. Data normality was tested by using Shapiro Wilk test. Median and (interquartile range [Q1 - Q3]) were used to express knowledge scores. For non- normally distributed variables, Wilcoxon signed-rank test was used to compare pre-session and post-session knowledge questions, while independent Mann-Whitney U test was used to compare between chain and individual pre-session knowledge questions. A $p$-value of $\leq 0.05$ was considered statistically significant.

\section{Results}

\section{Response rate}

The questionnaire was circulated to 1013 pharmacists; however only 792 community pharmacists accepted to participate $(44.45 \%$ male and $55.5 \%$ female) with an overall response rate of $(78.18 \%)$

\section{Knowledge}

For the PV and ADRs, 286 (36.11\%) and 230 (29.04\%) of the participants chose the correct definition respectively at baseline (before the educational session). After the educational session, they were improved to $740(93.43 \%)$ and $722(91.16 \%)$ respectively. Moreover, 182 (22.98\%) of the participants knew about the existence of EPVC at baseline, 'which was increased to 790 (99.75\%) after the educational session. Interestingly, 611 (77.78\%) of the participants admitted that all healthcare staff (Doctors, pharmacist, Nurses...etc.), Patients, patient's relatives and pharmaceutical companies are in charge of reporting an ADR and this activity should be a compulsory one. Similarly this was improved to 780 (98.48\%) after the educational session. Lastly, 176 (22.22\%) of the participants were aware about role and obligations of pharmaceutical companies in Egypt regarding PV reporting at baseline and this increased to $722(91.16 \%)$ after the educational session.

Pre-session median knowledge score was 4 [3-5] out of 7 and the overall classified score category of the sample was considered of insufficient knowledge level, while after the educational intervention post-session median knowledge score increased to7 [7-7] out of 7 achieving a good knowledge level. Moreover, on comparison of correct answers of pharmacist's knowledge regarding PV in the whole sample before and after the educational session, it is found that there was a significant difference and the educational session was successful in improving the basic preexisting knowledge regarding PV (Wilcoxon signed-rank test, $\mathrm{P}<0.001$ ). The full pre and post knowledge section questions and participants' answers are presented in table 1 .

We found in the pre-session questionnaire that chain pharmacists had significantly higher median knowledge scores than individual pharmacists with median scores of 4 [4-5] vs. 3 [3-3], re- 
Potential Role of Community Pharmacists in Pharmacovigilance: The Effectiveness of an Educational Intervention in Greater Cairo Province in Egypt

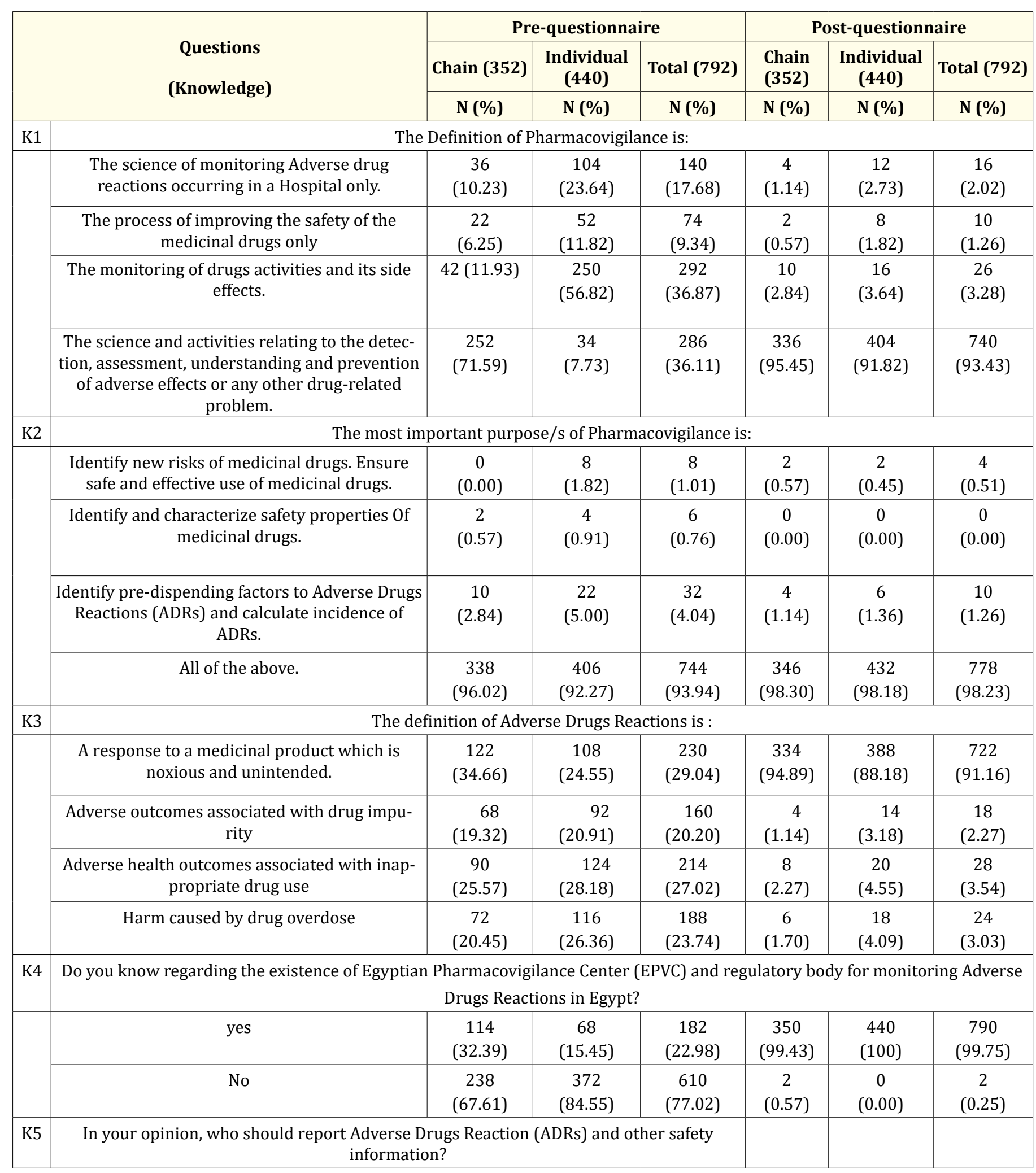


Potential Role of Community Pharmacists in Pharmacovigilance: The Effectiveness of an Educational Intervention in Greater Cairo Province in Egypt

\begin{tabular}{|c|c|c|c|c|c|c|c|}
\hline & Doctors & $\begin{array}{c}14 \\
(3.98)\end{array}$ & $\begin{array}{c}48 \\
(10.91)\end{array}$ & $62(7.83)$ & $\begin{array}{c}0 \\
(0.00)\end{array}$ & $\begin{array}{c}0 \\
(0.00)\end{array}$ & $\begin{array}{c}0 \\
(0.00)\end{array}$ \\
\hline & Nurses & $\begin{array}{c}0 \\
(0.00)\end{array}$ & $\begin{array}{c}0 \\
(0.00)\end{array}$ & $\begin{array}{c}0 \\
(0.00)\end{array}$ & $\begin{array}{c}0 \\
(0.00)\end{array}$ & $\begin{array}{c}0 \\
(0.00)\end{array}$ & $\begin{array}{c}0 \\
(0.00)\end{array}$ \\
\hline & Pharmacists & $\begin{array}{c}32 \\
(9.09) \\
\end{array}$ & $\begin{array}{c}32 \\
(7.27) \\
\end{array}$ & $\begin{array}{c}64 \\
(8.08) \\
\end{array}$ & $\begin{array}{c}2 \\
(0.57)\end{array}$ & $\begin{array}{c}10 \\
(2.27)\end{array}$ & $\begin{array}{c}12 \\
(1.52) \\
\end{array}$ \\
\hline & Patients & $\begin{array}{c}4 \\
(1.14)\end{array}$ & $\begin{array}{c}0 \\
(0.00)\end{array}$ & $\begin{array}{c}4 \\
(0.51)\end{array}$ & $\begin{array}{c}0 \\
(0.00)\end{array}$ & $\begin{array}{c}0 \\
(0.00)\end{array}$ & $\begin{array}{c}0 \\
(0.00)\end{array}$ \\
\hline & Relevant of patients & $\begin{array}{c}2 \\
(0.57)\end{array}$ & $\begin{array}{c}12 \\
(2.73)\end{array}$ & $\begin{array}{c}14 \\
(1.77)\end{array}$ & $\begin{array}{c}0 \\
(0.00)\end{array}$ & $\begin{array}{c}0 \\
(0.00)\end{array}$ & $\begin{array}{c}0 \\
(0.00)\end{array}$ \\
\hline & The Pharmaceutical companies & $\begin{array}{c}6 \\
(1.70)\end{array}$ & $\begin{array}{c}26 \\
(5.91)\end{array}$ & $\begin{array}{c}32 \\
(4.04)\end{array}$ & $\begin{array}{c}0 \\
(0.00)\end{array}$ & $\begin{array}{c}0 \\
(0.00)\end{array}$ & $\begin{array}{c}0 \\
(0.00)\end{array}$ \\
\hline & All of the above & $\begin{array}{c}294 \\
(83.52)\end{array}$ & $\begin{array}{c}322 \\
(73.18)\end{array}$ & $\begin{array}{c}611 \\
(77.78)\end{array}$ & $\begin{array}{c}350 \\
(99.43)\end{array}$ & $\begin{array}{c}430 \\
(97.73)\end{array}$ & $\begin{array}{c}780 \\
(98.48)\end{array}$ \\
\hline K6 & \multicolumn{7}{|c|}{ Which of the following safety information should be detected and reported in Pharmacovigilance system? } \\
\hline & Adverse Drugs Reactions. & $\begin{array}{c}0 \\
(0.00)\end{array}$ & $\begin{array}{c}0 \\
(0.00)\end{array}$ & $\begin{array}{c}0 \\
(0.00)\end{array}$ & $\begin{array}{c}0 \\
(0.00)\end{array}$ & $\begin{array}{c}0 \\
(0.00)\end{array}$ & $\begin{array}{c}0 \\
(0.00)\end{array}$ \\
\hline & Drugs used in pregnancy and lactation. & $\begin{array}{c}0 \\
(0.00)\end{array}$ & $\begin{array}{c}0 \\
(0.00)\end{array}$ & $\begin{array}{c}0 \\
(0.00)\end{array}$ & $\begin{array}{c}0 \\
(0.00)\end{array}$ & $\begin{array}{c}0 \\
(0.00)\end{array}$ & $\begin{array}{c}0 \\
(0.00)\end{array}$ \\
\hline & Transmission of infectious agent. & $\begin{array}{c}0 \\
(0.00)\end{array}$ & $\begin{array}{c}0 \\
(0.00)\end{array}$ & $\begin{array}{c}0 \\
(0.00)\end{array}$ & $\begin{array}{c}0 \\
(0.00)\end{array}$ & $\begin{array}{c}0 \\
(0.00) \\
\end{array}$ & $\begin{array}{c}0 \\
(0.00)\end{array}$ \\
\hline & Abuse, Misuse and off-label drugs. & $\begin{array}{c}0 \\
(0.00)\end{array}$ & $\begin{array}{c}0 \\
(0.00)\end{array}$ & $\begin{array}{c}0 \\
(0.00)\end{array}$ & $\begin{array}{c}0 \\
(0.00)\end{array}$ & $\begin{array}{c}0 \\
(0.00)\end{array}$ & $\begin{array}{c}0 \\
(0.00)\end{array}$ \\
\hline & Lack of efficacy. & $\begin{array}{c}0 \\
(0.00) \\
\end{array}$ & $\begin{array}{c}0 \\
(0.00) \\
\end{array}$ & $\begin{array}{c}0 \\
(0.00) \\
\end{array}$ & $\begin{array}{c}0 \\
(0.00) \\
\end{array}$ & $\begin{array}{c}0 \\
(0.00)\end{array}$ & $\begin{array}{c}0 \\
(0.00) \\
\end{array}$ \\
\hline & Medications error. & $\begin{array}{c}0 \\
(0.00) \\
\end{array}$ & $\begin{array}{c}0 \\
(0.00) \\
\end{array}$ & $\begin{array}{c}0 \\
(0.00)\end{array}$ & $\begin{array}{c}0 \\
(0.00) \\
\end{array}$ & $\begin{array}{c}0 \\
(0.00) \\
\end{array}$ & $\begin{array}{c}0 \\
(0.00) \\
\end{array}$ \\
\hline & Occupational exposure. & $\begin{array}{c}0 \\
(0.00) \\
\end{array}$ & $\begin{array}{c}0 \\
(0.00) \\
\end{array}$ & $\begin{array}{c}0 \\
(0.00) \\
\end{array}$ & $\begin{array}{c}0 \\
(0.00) \\
\end{array}$ & $\begin{array}{c}0 \\
(0.00) \\
\end{array}$ & $\begin{array}{c}0 \\
(0.00) \\
\end{array}$ \\
\hline & Overdose drug Rx. & $\begin{array}{c}0 \\
(0.00) \\
\end{array}$ & $\begin{array}{c}0 \\
(0.00) \\
\end{array}$ & $\begin{array}{c}0 \\
(0.00) \\
\end{array}$ & $\begin{array}{c}0 \\
(0.00) \\
\end{array}$ & $\begin{array}{c}0 \\
(0.00) \\
\end{array}$ & $\begin{array}{c}0 \\
(0.00) \\
\end{array}$ \\
\hline & Quality defect. & $\begin{array}{c}0 \\
(0.00) \\
\end{array}$ & $\begin{array}{c}0 \\
(0.00)\end{array}$ & $\begin{array}{c}0 \\
(0.00)\end{array}$ & $\begin{array}{c}0 \\
(0.00) \\
\end{array}$ & $\begin{array}{c}0 \\
(0.00)\end{array}$ & $\begin{array}{c}0 \\
(0.00)\end{array}$ \\
\hline & All of the above. & $\begin{array}{c}352 \\
(100.00)\end{array}$ & $\begin{array}{c}440 \\
(100.00)\end{array}$ & $\begin{array}{c}792 \\
(100.00)\end{array}$ & $\begin{array}{c}352 \\
(100.00)\end{array}$ & $\begin{array}{c}440 \\
(100.00)\end{array}$ & $\begin{array}{c}792 \\
(100.00)\end{array}$ \\
\hline
\end{tabular}

K7 Do you know that pharmaceutical companies in Egypt are obliged by National regulation to report any ADRs or other safety information to the Egyptian Pharmaceutical Vigilance Center?

\begin{tabular}{|l|c|c|c|c|c|c|}
\hline Yes & $\begin{array}{c}108 \\
(30.68)\end{array}$ & $\begin{array}{c}68 \\
(15.45)\end{array}$ & $\begin{array}{c}176 \\
(22.22)\end{array}$ & $\begin{array}{c}306 \\
(86.93)\end{array}$ & $\begin{array}{c}416 \\
(94.55)\end{array}$ & $\begin{array}{c}722 \\
(91.16)\end{array}$ \\
\hline No & $\begin{array}{c}244 \\
(69.32)\end{array}$ & $\begin{array}{c}372 \\
(84.55)\end{array}$ & $\begin{array}{c}616 \\
(77.78)\end{array}$ & $\begin{array}{c}46 \\
(13.07)\end{array}$ & $\begin{array}{c}24 \\
(5.45)\end{array}$ & $\begin{array}{c}70 \\
(8.84)\end{array}$ \\
\hline
\end{tabular}

Table 1: Knowledge questions and responses for pre and post-session questionnaires

(The correct answer is highlighted in grey for each of the listed questions). 
Potential Role of Community Pharmacists in Pharmacovigilance: The Effectiveness of an Educational Intervention in Greater Cairo Province in Egypt

spectively $(\mathrm{P}<0.001)$. However, in both cases the knowledge level were considered to be insufficient and requires improvement.

\section{Attitude}

The attitude of most of the participating community pharmacists concerning PV and ADRs was positive as 778 (98\%) of the community pharmacists agreed that reporting of ADR is necessary, 708 (89.39\%) think that Pharmacovigilance should be taught in undergraduate or post-graduate curriculum. About half of participating pharmacists (51.52\%) showed positive attitude towards pharmaceutical companies which provide and distribute educational materials as they reported that these companies should be trusted, $362(45.71 \%)$ of the participants considered that these companies are following regulations. Only 10 (1.26\%) got worried about using pharmaceutical companies products that provide or distribute educational materials (not promotional materials) and $12(1.52 \%)$ thought these companies have poor quality products. Interestingly, none of the participants had any negative attitudes towards pharmaceutical companies that include all warring and precautions in its products package insert. Community pharmacists' Attitudes questions and responses are presented in table 2.

\section{Practices}

The majority of the participating community pharmacists

\begin{tabular}{|c|c|c|c|c|}
\hline \multirow{3}{*}{\multicolumn{2}{|c|}{$\begin{array}{l}\text { Questions } \\
\text { (Attitude) }\end{array}$}} & \multicolumn{3}{|c|}{ Post-training session } \\
\hline & & \multirow{2}{*}{$\begin{array}{c}\text { Chain (352) } \\
\mathrm{N}(\%) \\
\end{array}$} & \multirow{2}{*}{\begin{tabular}{c|} 
Individual (440) \\
$\mathrm{N}(\%)$ \\
\end{tabular}} & \multirow{2}{*}{$\begin{array}{c}\text { Total (792) } \\
\mathrm{N}(\%)\end{array}$} \\
\hline & & & & \\
\hline \multirow[t]{4}{*}{$\begin{array}{l}\text { Do you think reporting of adverse drug reaction is } \\
\text { necessary? }\end{array}$} & Yes & $\begin{array}{c}348 \\
(98.86) \\
\end{array}$ & $\begin{array}{c}430 \\
(97.73)\end{array}$ & $\begin{array}{c}778 \\
(98.23) \\
\end{array}$ \\
\hline & No & $0(0.00)$ & $0(0.00)$ & $0(0.00)$ \\
\hline & Don't Know & $0(0.00)$ & $0(0.00)$ & $0(0.00)$ \\
\hline & May be & $4(1.14)$ & $10(2.27)$ & $14(1.77)$ \\
\hline \multirow{4}{*}{$\begin{array}{l}\text { Do you think Pharmacovigilance should be taught in } \\
\text { under-graduate or post-graduate curriculum? }\end{array}$} & Yes & $332(94.32)$ & $376(85.45)$ & 708 (89.39) \\
\hline & No & $4(1.14)$ & $50(11.36)$ & $54(6.82)$ \\
\hline & Don't Know & $0(0.00)$ & $0(0.00)$ & $0(0.00)$ \\
\hline & May be & $16(4.55)$ & $14(3.18)$ & $30(3.79)$ \\
\hline \multirow{4}{*}{$\begin{array}{l}\text { What is your perception regarding pharmaceutical } \\
\text { companies that provide and distribute educational } \\
\text { materials } \\
\text { (not promotional materials)? }\end{array}$} & Trusted & $178(50.57)$ & $230(52.27)$ & $408(51.52)$ \\
\hline & Follow regulations & $166(47.16)$ & $196(44.55)$ & $362(45.71)$ \\
\hline & $\begin{array}{l}\text { I got worried about using } \\
\text { their products }\end{array}$ & $\begin{array}{c}6 \\
(1.70)\end{array}$ & $\begin{array}{c}4 \\
(0.91)\end{array}$ & $\begin{array}{c}10 \\
(1.26)\end{array}$ \\
\hline & Have poor quality products & $2(0.57)$ & $10(2.27)$ & $12(1.52)$ \\
\hline \multirow{4}{*}{$\begin{array}{l}\text { What do you think about pharmaceutical companies } \\
\text { that include all warring and precautions in its prod- } \\
\text { ucts insert? }\end{array}$} & Trusted & $124(35.23)$ & $226(51.36)$ & $350(44.19)$ \\
\hline & Follow regulations & $228(64.77)$ & $214(48.64)$ & $442(55.81)$ \\
\hline & $\begin{array}{l}\text { I got worried about using } \\
\text { their products }\end{array}$ & $0(0.00)$ & $0(0.00)$ & $0(0.00)$ \\
\hline & Have poor quality products & $0(0.00)$ & $0(0.00)$ & $0(0.00)$ \\
\hline
\end{tabular}

Table 2: Attitudes of community pharmacists towards pharmacovigilance. 
Potential Role of Community Pharmacists in Pharmacovigilance: The Effectiveness of an Educational Intervention in Greater Cairo Province in Egypt

showed low level of ADR reporting and PV practices as only 84 $(10.61 \%)$ had read and learnt about PV, while only two participants had already reported previously to EPVC. However, more than half of the participants 446 (56.31\%) had experienced ADRs and other safety information with their patients during their community pharmacy practice. About half of the participants 360 (45.45\%) reported that the main factor that can help to detect an ADR was a consultation started by the patient, however 339 participant $(42.8 \%)$ reported that they should start and ask the patients about any possible ADRs happened to them. Practice questions and responses are presented in table 3.

On the other hand, the most reported factor $(61.11 \%)$ that discourage community pharmacists from reporting ADRs and other

\begin{tabular}{|c|c|c|c|c|}
\hline & \multirow{3}{*}{$\begin{array}{l}\text { Questions } \\
\text { (Practice) }\end{array}$} & \multicolumn{3}{|c|}{ Post-training session } \\
\hline & & \multirow{2}{*}{$\begin{array}{l}\text { Chain } \\
(352)\end{array}$} & \multirow{2}{*}{$\begin{array}{c}\begin{array}{c}\text { Individual } \\
(440)\end{array} \\
\mathrm{N}(\%)\end{array}$} & \multirow{2}{*}{$\begin{array}{r}\text { Total } \\
(792) \\
N(\%) \\
\end{array}$} \\
\hline & & & & \\
\hline \multirow[t]{4}{*}{$\begin{array}{l}\text { Have you ever read any article of Phar- } \\
\text { macovigilance? }\end{array}$} & Yes & $\begin{array}{c}72 \\
20.45)\end{array}$ & $\begin{array}{c}12 \\
(2.73)\end{array}$ & $\begin{array}{c}84 \\
(10.61)\end{array}$ \\
\hline & No & $\begin{array}{c}280 \\
(79.55)\end{array}$ & $\begin{array}{c}406 \\
(92.27) \\
\end{array}$ & $\begin{array}{c}686 \\
(86.62) \\
\end{array}$ \\
\hline & Don't Know & $\begin{array}{c}0 \\
(0.00)\end{array}$ & $\begin{array}{c}0 \\
(0.00) \\
\end{array}$ & $\begin{array}{c}0 \\
(0.00) \\
\end{array}$ \\
\hline & May be & $\begin{array}{c}0 \\
(0.00)\end{array}$ & $\begin{array}{c}0 \\
(0.00)\end{array}$ & $\begin{array}{c}0 \\
(0.00)\end{array}$ \\
\hline \multirow{4}{*}{$\begin{array}{l}\text { According to your experience, the main } \\
\text { thing that can help you to detect the } \\
\text { ADRs is: }\end{array}$} & Consultation started by Patient & $\begin{array}{c}79 \\
(22.44)\end{array}$ & $\begin{array}{c}281 \\
(63.86)\end{array}$ & $\begin{array}{c}360 \\
(45.45)\end{array}$ \\
\hline & Asking the patient & $\begin{array}{c}237 \\
(67.33)\end{array}$ & $\begin{array}{c}102 \\
(23.18)\end{array}$ & $\begin{array}{c}339 \\
(42.80)\end{array}$ \\
\hline & Discussion with the physicians & $\begin{array}{c}36 \\
(10.23)\end{array}$ & $\begin{array}{c}57 \\
(12.95)\end{array}$ & $\begin{array}{c}93 \\
(11.74)\end{array}$ \\
\hline & Others & $\begin{array}{c}0 \\
(0.00)\end{array}$ & $\begin{array}{c}0 \\
(0.00)\end{array}$ & $\begin{array}{c}0 \\
(0.00)\end{array}$ \\
\hline \multirow{4}{*}{$\begin{array}{c}\text { Have you ever experienced adverse drug } \\
\text { reactions or other safety information in } \\
\text { your patient during your professional } \\
\text { practice? }\end{array}$} & Yes, I have experienced an ADRs. & $\begin{array}{c}37 \\
(10.51) \\
\end{array}$ & $\begin{array}{c}44 \\
(10.00) \\
\end{array}$ & $\begin{array}{c}81 \\
(10.23) \\
\end{array}$ \\
\hline & Yes, I have experienced other safety info. & $\begin{array}{c}1 \\
(0.28)\end{array}$ & $\begin{array}{c}8 \\
(1.82) \\
\end{array}$ & $\begin{array}{c}9 \\
(1.14)\end{array}$ \\
\hline & $\begin{array}{l}\text { Yes, I have experienced both ADRs and other safety } \\
\text { info. }\end{array}$ & $\begin{array}{c}216 \\
(61.36)\end{array}$ & $\begin{array}{c}230 \\
(52.27)\end{array}$ & $\begin{array}{c}446 \\
(56.31) \\
\end{array}$ \\
\hline & $\begin{array}{l}\text { No, I have NOT experienced ADRs nor other safety } \\
\text { info. }\end{array}$ & $\begin{array}{c}99 \\
(28.13) \\
\end{array}$ & $\begin{array}{c}196 \\
(44.55)\end{array}$ & $\begin{array}{c}295 \\
(37.25) \\
\end{array}$ \\
\hline \multirow{4}{*}{$\begin{array}{l}\text { Have you ever reported Adverse Drug } \\
\text { Reactions (ADRs) or other safety infor- } \\
\text { mation to the Pharmaceutical vigilance } \\
\text { centre? }\end{array}$} & Yes, I have reported an ADRs. & $\begin{array}{c}0 \\
) 0.00(\end{array}$ & $\begin{array}{c}0 \\
0.00(\end{array}$ & $\begin{array}{c}0 \\
) 0.00(\end{array}$ \\
\hline & Yes, I have reported other safety info. & $\begin{array}{c}0 \\
) 0.00(\end{array}$ & $\begin{array}{c}0 \\
j 0.00(\end{array}$ & $\begin{array}{c}0 \\
) 0.00(\end{array}$ \\
\hline & $\begin{array}{l}\text { Yes, I have reported both ADRs and other safety } \\
\text { info. }\end{array}$ & $\begin{array}{c}2 \\
(0.57)\end{array}$ & $\begin{array}{c}0 \\
j 0.00(\end{array}$ & $\begin{array}{c}2 \\
(0.25)\end{array}$ \\
\hline & $\begin{array}{l}\text { No, I have NOT reported ADRs nor other safety } \\
\text { info. }\end{array}$ & $\begin{array}{c}348 \\
(99.43)\end{array}$ & $\begin{array}{c}440 \\
(100.00)\end{array}$ & $\begin{array}{c}788 \\
(99.49)\end{array}$ \\
\hline
\end{tabular}

Table 3: Practices questions and responses. 
safety information was the lack of time to report as they carry out many tasks during their working hours. In addition, $224(28.28 \%)$ vindicate under reporting as they don't know how to report. A minor group of $60(7.57 \%)$ pharmacists had negative perceptions of a single unreported case may not affect ADR database. Figure 1 shows the different reasons behind low reporting ADRs. Among many methods that may be used for ADRs reporting (Figure 2), the EPVC social media accounts such as Facebook page had been selected by $432(54.55 \%)$ as the best and convenient method to report the ADRs.

\section{Discussion}

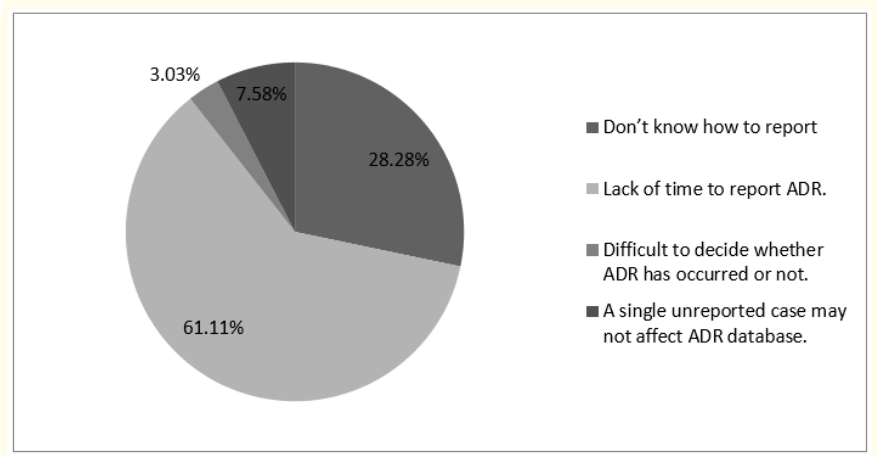

Figure 1: Reasons of underreporting Adverse Drug Reactions among Egyptian community pharmacists.

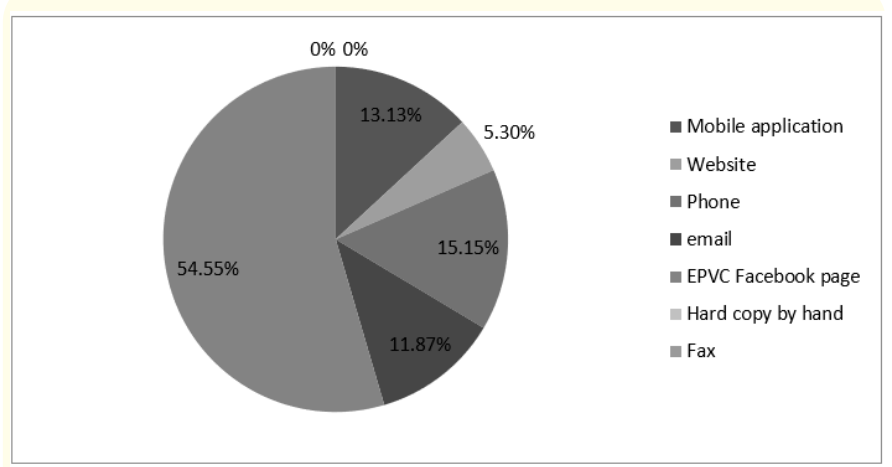

Figure 2: Methods used for reporting of Adverse Drug Reactions.

ADRs resemble a high risk of therapeutic failure and negative economic impact. PV is a potential tool to avoid or reduce ADRs. Community pharmacists are considered one of the pillars for the success of PV systems through their potential for spontaneous ADR reporting. To the best of our knowledge, this was the first study with a large sample to assess knowledge, attitudes and practices of Egyptian community pharmacists about PV.

In the current study, it was found that the majority $(63.89 \%$ and $70.96 \%$ ) of the participating community pharmacists showed low degree of knowledge regarding the definitions of PV and ADRs, respectively. Interestingly, community pharmacists working in chain pharmacies showed a significantly higher degree of knowledge than those working in private or individual pharmacies. The continuing pharmaceutical educational and training programs that are provided constantly to pharmacists working in chain pharmacies could be the reason for increasing their knowledge and awareness regarding PV. On the contrary, pharmacists working in individual pharmacies are not required to receive such educational programs and usually have to consider self-education which in most cases is not constant and with limited capacities.

In the current study, it was also found that almost all participating community pharmacists (77.02\%) -before the educational session- did not know about national ADRs reporting system. This is also the case in the Kingdom of Saudi Arabia, where $86.8 \%$ of community pharmacists included in a study were not aware of the country's ADRs reporting program [23].

In United Arab Emirates, almost a similar situation where 60\% of the community pharmacists did not know how or where to report an ADR and the community pharmacists admitted facing some challenges for ADRs reporting because of their lack of knowledge in reporting [24].

Interestingly, in the pre-session questionnaire all the participants knew the basic safety information that should be detected and reported. Additionally, the majority of the participants (77.78\%) admitted that all HCPs share the responsibilities of reporting ADRs and therefore more educational and awareness programs to increase PV and ADRs reporting should be designed to target different practitioners. Such practices will increase and enhance the overall rate of reporting and PV processes [25].

We assessed the efficacy of short educational intervention on the participating pharmacists. After receiving the brief session of PV and ADRs, the knowledge scores were found to have increased significantly (Pre-session median knowledge score 4 [3-5] vs post-session median knowledge score 7 [7-7], $(\mathrm{P}<0.001)$. This 
proves the efficacy of such programs which needs to be incorporated in large scale to promote for PV and ADRs reporting across the pharmaceutical society [26-28]. As only 182 (22.98\%) of the participants in the pre-questionnaire knew about the existence of EPVC, this could explain their attitude and practice towards the PV as they did not have the knowledge about where and how they should report ADRs. This percentage increased after-training session as $99.75 \%$ of the participants became aware of the existence of EPVC and knew the processes of reporting ADRs. Similarly, in an Iranian study, the percentage of HCPs who were encouraged to report ADRs was raised from $2.4 \%$ to $11 \%$ [29]. Additionally, in Nepal, Jha., et al. [27], found that the knowledge and attitude scores of the community pharmacists were improved after an educational intervention. Moreover, in Nigeria, Opadeyi., et al. [28], reported a positive impact on the knowledge and practice of PV with a lessthan-impressive change in attitude after an incorporating an educational intervention to the participating HCPS.

Concerning the Egyptian community pharmacists' attitude and practice towards PV, the majority of the responders admitted having a positive attitude towards their role in ADR reporting and this activity was even seen as one of their core duties and this is similar to the attitude of Kuwaiti pharmacists in a similar published study [9]. As for PV training/education, most of the community pharmacists (86.62\%) admitted that they have never received any training/education and never read any article of PV and this percentage is high and similar to the percentage reported in a study conducted in Lebanon (72.6\%) [4]. This percentage could be the driving reason in which the majority (89.39\%) as well responded that incorporating PV education in under-graduate or post graduate curriculum is necessary and this finding is similar to previous studies conducted among HCPs [30-32]. Also In Jordan, community pharmacists suggested to include this topic as a part of teaching curriculum, as well as to perform a number of educational courses and workshops by the specialized authorities [33].

What makes this study unique is assessing the community pharmacists' attitude towards pharmaceutical companies PV activities. The overall attitude was positive, even when questioning about warning and precautions included in products package insert. None of the participants had any negative attitude, fear or concern regarding that, and more than half of the participants responded to the distribution of educational materials by pharmaceutical companies positively that the company is compliant with national authority guidelines and trusted.
These data represent a great opportunity for both pharmaceutical companies and EPVC to play their role in raising the awareness about PV and medication safety. Regarding their practices, the factor that discourage the participating Egyptian community pharmacists (61.11\%) from reporting ADRs/other safety information the most, is lack of time to report as there are many tasks, such as giving drug advice and dispensing the drug, and that there is not enough time for rest and this was a concern from the side of many participants and that is why we can see in Turkey, Great Britain, and USA some pharmacists considered that ADRs reporting disrupts the workflow and it is considered as an additional duty and not an integral part of their professional duties [34-36]. In addition, 224 (28.28\%) vindicated under reporting by that they do not know how to report (Figure 1).

In this study, Facebook page had been selected by 432 (54.55\%) as the best and convenient method to report the ADRs. However, in a similar study in Gujarat, India, $40.59 \%$ of the participants preferred to report ADRs via e-mail/on web site and the same in Belgium where the website was contacted for recent numbers on spontaneous ADR reporting by HCPs in general and pharmacists in particular in a similar study too $[37,38]$.

\section{Future Directions}

International society of Pharmacovigilance (ISoP) - Egypt Chapter working in establishment a national educational program about drug monitoring includes all governorates of Egypt to consolidate community pharmacists in the ADRs reporting process.

\section{Study Limitation}

Due to the long duration of the interview, the current questionnaires did not include and collect important socio-demographic data which could explain the variation among the respondents. Additionally, the use of a questionnaires -in some instances- may not always be accurate due to problems in question understanding, question-wording, recall deficiency and over/under evaluating the questions, which can lead to a possible information bias. The questionnaire was distributed in great Cairo only, there may be variation according to the governorate and education levels of pharmacists. Social desirability bias and non-respondent bias may also be considered as potential limitations to current the research. Moreover, the attitude and practices have been evaluated after the session only as most of the community pharmacists were expected to know little about PV and ADR so attitude and practices could not be evaluated at baseline. 


\section{Conclusion}

Educational interventions are an effective tool to raise and improve the knowledge of Egyptian community pharmacists towards $\mathrm{PV}$ and ADRs reporting as well as encouraging them to include reporting roles into their duties. We recommend conducting similar studies with questionnaires with more data collection and on nationwide scale to capture the exact degree of knowledge of the community pharmacists and design as well as deliver tailored educational programs on $\mathrm{PV}$ and ADRs reporting, which will ultimately improve the ADRs reporting rates and enhance medication safety and health care outcomes in Egypt.

\section{Acknowledgements}

The authors would like to thank all the pharmacovigilance specialists of the Egyptian Pharmaceutical Vigilance Center (EPVC) for their training to the interviewers. They would also like to thank Yoanis Adel, Mahmoud Eltobgy and Nour-Alhuda Nazzal for helping in passing the questionnaires and data entry.

\section{Bibliography}

1. World Health Organization. Quality Assurance and Safety of Medicines Team. "Safety of medicines : a guide to detecting and reporting adverse drug reactions : why health professionals need to take action". World Health Organization (2002).

2. Gupta SK., et al. "A questionnaire study on the knowledge, attitude, and the practice of pharmacovigilance among the healthcare professionals in a teaching hospital in South India". Perspectives in Clinical Research 6.1 (2015): 45-52.

3. Fornasier G., et al. "An historical overview over Pharmacovigilance". International Journal of Clinical Pharmacy 40.4 (2018): 744-747.

4. Hallit S., et al. "Medication safety knowledge, attitude, and practice among hospital pharmacists in Lebanon". Journal of Evaluation in Clinical Practice 25.2 (2019): 323-339.

5. Beninger P. "Pharmacovigilance: An Overview”. Clinical Therapy 40.12 (2018): 1991-2004.

6. Olowofela A., et al. "Pharmacovigilance in Nigeria: An Overview". Pharm Med 30 (2016): 87-94.

7. Pitts PJ., et al. "21st century pharmacovigilance: efforts, roles, and responsibilities". Lancet Oncology 17.11 (2016): e486e492.
8. Stolk RP. “Screening for diabetes". BMJ 335.7618 (2007): 457 458.

9. Alsaleh FM., et al. "Knowledge, attitude and practices of pharmacovigilance and adverse drug reaction reporting among pharmacists working in secondary and tertiary governmental hospitals in Kuwait". Saudi Pharmaceutical Journal 25.6 (2017): 830-837.

10. Alshammari TM., et al. "Pharmacovigilance Systems in Arab Countries: Overview of 22 Arab Countries". Drug Safety 42.7 (2019): 849-868.

11. Othman GQ., et al. "Knowledge and Perception about Pharmacovigilance among Pharmacy Students of Universities in Sana'a Yemen". Journal of Clinical and Diagnostic Research 11.6 (2017): FC09-FC13.

12. Jose J., et al. "A cross sectional pilot study on assessing the knowledge, attitude and behavior of community pharmacists to adverse drug reaction related aspects in the Sultanate of Oman". Saudi Pharmaceutical Journal 22.2 (2014): 163-169.

13. Peymani P., et al. "Knowledge, attitude and practice of General Practitioners towards adverse drug reaction reporting in South of Iran, Shiraz (Pharmacoepidemiology report)". International Journal of Risk and Safety in Medicine 28.1 (2016): 25-31.

14. UMC | WHO Programme for International Drug Monitoring.

15. Upsala report 16. Retrieved from the Upsala Monitoring Center - World Health Organization (2001).

16. SAFETY MONITORING of MEDICINAL PRODUCTS: Guidelines for setting up and running a Pharmacovigilance Centre. Retrieved from the Upsala Monitoring Center - World Health Organization (2000).

17. Alraie NA., et al. "Adverse drug reactions reporting: a questionnaire-based study on Egyptian pharmacists' attitudes following an awareness workshop". Journal of Evaluation in Clinical Practice 22.3 (2016): 349-355.

18. Newlands RS., et al. "Quality improvement of community pharmacy services: a prioritisation exercise". International Journal of Pharmacy Practice 26.1 (2018): 39-48.

19. Leape LL., et al. "Pharmacist participation on physician rounds and adverse drug events in the intensive care unit". JAMA 282.3 (1999): 267-270. 
20. HEMA NG and BK. "Pharmacovigilance: The Extent of Awareness Among the Final Year Students, Interns and Postgraduates in a Government Teaching Hospital". Journal of Clinical and Diagnostic Research 6.7 (2012): 1248-1253.

21. Nisa ZU., et al. "Assessment of knowledge, attitude and practice of adverse drug reaction reporting among healthcare professionals in secondary and tertiary hospitals in the capital of Pakistan". Saudi Pharmaceutical Journal 26.4 (2018): 453-461.

22. Burns KE., et al. "A guide for the design and conduct of self-administered surveys of clinicians". CMAJ 179.3 (2008): 245-252.

23. Mahmoud MA., et al. "Community pharmacists' knowledge, behaviors and experiences about adverse drug reaction reporting in Saudi Arabia". Saudi Pharmaceutical Journal 22.5 (2014): 411-418.

24. Said ASA., et al. "Adverse Drug Reaction Reporting Practices Among United Arab Emirates Pharmacists and Prescribers". Hospital Pharmacy 52.5 (2017): 361-366.

25. Ganesan S., et al. "The Impact of the Educational Intervention on Knowledge, Attitude, and Practice of Pharmacovigilance toward Adverse Drug Reactions Reporting among Health-care Professionals in a Tertiary Care Hospital in South India". Journal of Natural Science, Biology, and Medicine 8.2 (2017): 203209.

26. Varallo FR., et al. "Effectiveness of pharmacovigilance: multifaceted educational intervention related to the knowledge, skills and attitudes of multidisciplinary hospital staff". Clinics (Sao Paulo) 72.1 (2017): 51-57.

27. Jha N., et al. "Effect of an educational intervention on knowledge and attitude regarding pharmacovigilance and consumer pharmacovigilance among community pharmacists in Lalitpur district, Nepal". BMC Research Notes 10.1 (2017): 4.

28. Opadeyi AO., et al. "Assessment of the state of pharmacovigilance in the South-South zone of Nigeria using WHO pharmacovigilance indicators". BMC Pharmacology and Toxicology 19.1 (2018): 27.

29. Khalili H., et al. "Improvement of knowledge, attitude and perception of healthcare workers about ADR, a pre- and post-clinical pharmacists' interventional study". BMJ Open 2.1 (2012): e000367.

30. Reumerman M., et al. "Urgent need to modernize pharmacovigilance education in healthcare curricula: review of the literature". European Journal of Clinical Pharmacology 74.10 (2018): 1235-1248.
31. Arici MA., et al. "Short and long-term impact of pharmacovigilance training on the pharmacovigilance knowledge of medical students". Indian Journal of Pharmacology 47.4 (2015): 436439.

32. Hartman J., et al. "A global view of undergraduate education in pharmacovigilance". European Journal of Clinical Pharmacology 73.7 (2017): 891-899.

33. Suyagh M., et al. "Pharmacist's knowledge, practice and attitudes toward pharmacovigilance and adverse drug reactions reporting process". Saudi Pharmaceutical Journal 23.2 (2015): 147-153.

34. Sweis D and Wong IC. "A survey on factors that could affect adverse drug reaction reporting according to hospital pharmacists in Great Britain". Drug Safety 23.2 (2000): 165-172.

35. Gavaza P., et al. "Influence of attitudes on pharmacists' intention to report serious adverse drug events to the Food and Drug Administration". British Journal of Clinical Pharmacology 72.1 (2011): 143-152.

36. Toklu HZ and Uysal MK. "The knowledge and attitude of the Turkish community pharmacists toward pharmacovigilance in the Kadikoy district of Istanbul". Pharmacy World and Science 30.5 (2008): 556-562.

37. Upadhyaya HB., et al. "Knowledge, attitude and practices toward pharmacovigilance and adverse drug reactions in postgraduate students of Tertiary Care Hospital in Gujarat". Journal of Advanced Pharmaceutical Technology and Research 6.1 (2015): 29-34.

38. De Meestere D and Saevels J. "Belgian community pharmacists' pharmacovigilance perspective and practice". Research in Social and Administrative Pharmacy 15.12 (2019): 1446-1452.

\section{Assets from publication with us}

- Prompt Acknowledgement after receiving the article

- Thorough Double blinded peer review

- Rapid Publication

- Issue of Publication Certificate

- High visibility of your Published work

Website: www.actascientific.com/

Submit Article: www.actascientific.com/submission.php Email us: editor@actascientific.com

Contact us: +919182824667 